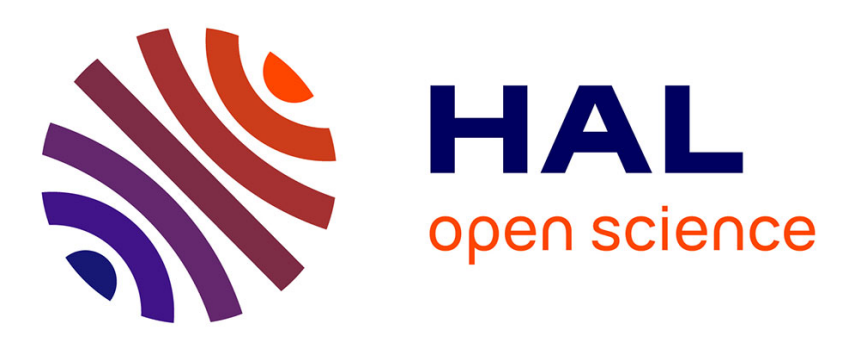

\title{
Selection of green solvents for organic photovoltaics by reverse engineering
}

\author{
Jing Wang, Ivonne Rodriguez-Donis, Sophie Thiebaud-Roux, Olzhas A \\ Ibraikulov, Nicolas Leclerc, Patrick Lévêque, Vincent Gerbaud, Markus \\ Kohlstädt, Thomas Heiser
}

\section{To cite this version:}

Jing Wang, Ivonne Rodriguez-Donis, Sophie Thiebaud-Roux, Olzhas A Ibraikulov, Nicolas Leclerc, et al.. Selection of green solvents for organic photovoltaics by reverse engineering. Molecular Systems Design \& Engineering, 2021, 10.1039/D1ME00151E . hal-03445381

\section{HAL Id: hal-03445381 \\ https://hal.science/hal-03445381}

Submitted on 3 Dec 2021

HAL is a multi-disciplinary open access archive for the deposit and dissemination of scientific research documents, whether they are published or not. The documents may come from teaching and research institutions in France or abroad, or from public or private research centers.
L'archive ouverte pluridisciplinaire HAL, est destinée au dépôt et à la diffusion de documents scientifiques de niveau recherche, publiés ou non, émanant des établissements d'enseignement et de recherche français ou étrangers, des laboratoires publics ou privés. 


\title{
Selection of green solvents for organic photovoltaics by reverse engineering
}

Jing Wang ${ }^{a}$, Ivonne Rodriguez-Donis*b, Sophie Thiebaud-Roux ${ }^{\mathrm{b}}$, Olzhas A. Ibraikulov ${ }^{\mathrm{a}}$, Nicolas Leclerc $^{c}$, Patrick Lévêque ${ }^{\mathrm{a}}$, Vincent Gerbaud ${ }^{\mathrm{d}}$, Markus Kohlstädt ${ }^{\mathrm{e}}$ and Thomas Heiser*a

\begin{abstract}
For a sustainable scale-up of solution-processed organic photovoltaic modules, the replacement of toxic solvents, generally used at laboratory scale, by alternative "green" solvents with a reduced impact on the environment and human health is a critical pre-requisite. Yet, because of the complex relationship between solvent properties and device performance, the selection of alternative solvents relies primarily on time-consuming and costly trial-and-error approaches. In this work we propose a new methodology involving prediction of molecular properties and reverse design for a more efficient and less empirical selection of green and bio-sourced solvents. The method is applied to four different small molecule- and polymer based donor-acceptor blends. It allows to establish lists of possible alternative solvents ranked quantitavely by a global performance function encompassing all target properties. The actual performance of the highest ranked solvents are evaluated by using the selected solvents to elaborate photovoltaic devices and comparing the power conversion efficiencies with those obtained with devices processed from halogenated solutions. In all cases, the photovoltaic performances obtained with the alternative solvents are similar or superior to those of the standard devices, confirming the relevance of the new solvent selection method for solution-processed organic photovoltaic devices.
\end{abstract}

\section{Introduction}

Organic Photovoltaics (OPV) is seen as a promising alternative to conventional photovoltaic technologies due to the possibility of producing lightweight flexible modules at low cost. The recently reported significant increase in power conversion efficiency (PCE) of OPV devices strengthens further the potential for this technology to contribute to large-scale renewable energy production. ${ }^{1-3,74}$ When it comes to the industrial development of OPV modules however, the safe, ecofriendly and economical manufacturing is still an important open issue and will depend on the availability of non-toxic solvents compatible with roll-to-roll production of organic modules. Indeed, at the laboratory scale, the processing of organic solar cells is generally done by using halogenated solvents such as chloroform $(\mathrm{CF})^{2-4}, 1,2$-dichlorobenzene $(0$ $D C B)^{5-8}$ or chlorobenzene $(C B)^{1,8-11}$, since these provide good solubility for many semiconducting polymers and allow to reach high performances. However, halogenated solvents are toxic and banned for the production of large area devices. There is thus an urgent need to identify alternative solvents that allow to process OPV devices with a negligible impact on the environment and human health, without reducing the energy conversion efficiency.

Of the many new materials that have recently been reported to improve the efficiency of OPV devices, only few examples have been processed with non- or less toxic solvents. For instance, $o$-xylene and 1-phenylnaphthalene were used by Zhao et al. ${ }^{12}$ to process a novel polymer- and non-fullerene acceptor (NFA) based blend, leading to a PCE of $13.1 \%$. The same solvent and additive combination was used by Ibraikulov et al. to produce blade coated large area ITO-free OPV modules $\left(66 \mathrm{~cm}^{2}\right)$ with a PCE of more than $6 \% .{ }^{13} \mathrm{Hong}$ et al. were able to elaborate devices based on another donor-acceptor blend with 16\% PCE from non-halogenated tetrahydrofuran (THF) ${ }^{14}$.
Toluene and 1,2,4-trimethylbenzene are other reported examples of alternative solvents although still classified as hazardous. ${ }^{15-19}$ The most promising recent example is 2-methyl anisole (2-MA), which can be used as a food additive in industry and has allowed to achieve a PCE of $9.6 \%$ with a polymerfullerene blend..$^{20}$ The utilization of water-dispersible organic semiconductor nanoparticles (NPs) is a distinct approach that can be as well followed to avoid toxic solvents. ${ }^{21}$ A PCE of around $7 \%$ has recently been reached using NPs of a low bandgap polymer and a non-fullerene acceptor. ${ }^{22}$ However, the perspectives of this method rely on the development of customized materials with appropriate physico-chemical properties. ${ }^{21}$ Despite these encouraging results, the selection of alternative solvents is still a challenging endeavour that has so far mostly relied on tedious experimental trial-and-error approaches. The search for new solvents is indeed requiring the simultaneous consideration of many physico-chemical properties that can influence the device performances. As new donor and acceptor materials are continuously being designed to achieve solar cells with even higher performance, a more efficient and less empirical method for identifying non-toxic solvents would thus be a major advantage. In addition, since sustainability is equally desirable, solvents produced from biobased resources would be particularly attractive. ${ }^{23}$ However, biosolvents are less versatile than most chlorinated or hydrocarbon solvents, rendering the search for efficient biosourced solvents even more difficult. It is worth noting that the demand for non-toxic solvents is likewise important for organic and hybrid devices other than OPV, such as solution-processed organic light-emitting diodes (OLEDs), field-effect transistors (OFETs), organic photodiodes (OPDs) or perovskite solar cells. ${ }^{24-}$ 28

Reverse engineering is nowadays an established approach for designing solvents with multiple properties. It follows the Computer Aided Molecular Design (CAMD) ${ }^{29-32}$ precepts by first 
defining a set of target values for a group of selected physicochemical properties and by leading the construction in silico of molecular structures that best satisfy them. Recently, an innovative CAMD tool, called IBSS ${ }^{\circledR}$ CAMD, ${ }^{33}$ has been developed by Juliette Heintz et al. to design alternative solvents and eventually biosolvents. ${ }^{34,35}$ IBSS ${ }^{\circledR}$ CAMD designs molecular structures by imposing building blocks, including bio-based ones, as starting fragments to ensure the development of solvents that can be synthesized from bio-based resources. Some recent examples of the utilization of IBSS ${ }^{\circledR}$ CAMD include the substitution of acetone and methyl ethyl ketone (MEK) by furfural derivatives to dissolve two epoxy resin prepolymers, as well as bisphenol A diglycidyl ether (DGEBA), triglycidyl paminophenol ether (TGPA) ${ }^{36}$ and glycerol derivatives to solubilize nitrocellulose ${ }^{37}$. IBSS ${ }^{\circledR}$ CAMD has also been applied to generate ricinoleic acid derivatives aiming to find new biolubricants from a biomass feedstock ${ }^{38}$. Herein, we use the IBSS ${ }^{\circledR}$ CAMD engineering methodology for the first time to find alternatives for organic photovoltaic materials. The method is applied on four different small molecule- and polymer- based donor-acceptor blends to demonstrate its ability to identify alternative solvents with targeted properties for the development of efficient solar cells. Poly(3-hexylthiophene) (P3HT) and PF2, a fluorinated low band-gap copolymer, are used as electron donors, while [6,6]-phenyl-C71-butyric acid methyl ester $\left(\mathrm{PC}_{71} \mathrm{BM}\right)$ and ethylhexyl-rhodaninebenzothiadiazole-coupled indacenodithiophene (EH-IDTBR) as electron acceptors. $\mathrm{P} 3 \mathrm{HT}: \mathrm{PC}_{71} \mathrm{BM}$ blends have been extensively studied for OPV applications, but only few studies have dealt with green solvent selection. ${ }^{15,39}$ They are therefore a good reference material for testing the proposed methodology, even though the expected power conversion efficiency is lower than current state-of-the-art solar cells. ${ }^{40}$ PF2 is a high performance fluorinated electron-donor copolymer that has been reported to achieve a power conversion efficiency over $10 \%$ in blends with $\mathrm{PC}_{71} \mathrm{BM}$ and more than $12 \%$ in ternary blends. ${ }^{41,42}$ The rather low solubility of PF2 in halogenated solvents at room temperature requires the blends to be processed at elevated temperatures and makes the identification of alternative solvents even more challenging. EH-IDTBR is a non-fullerene acceptor that has allowed to improve the PCE of P3HT-based devices. ${ }^{43-45}$ We therefore also applied our solvent selection method to P3HT:EH-IDTBR and PF2:EH-IDTBR blends.

In the following, we will first present the steps that need to be considered when applying IBSS ${ }^{\circledR}$ CAMD for solvent selection. Next, the method is used to find environmentally friendly and possibly bio-based candidate solvents for $\mathrm{P} 3 \mathrm{HT}: \mathrm{PC}_{71} \mathrm{BM}$, PF2:PC ${ }_{71} B M, P 3 H T: E H-I D T B R$, and PF2:EH-IDTBR blends. In the last section, the photovoltaic performances of devices processed from selected green solvents are compared to those obtained with halogenated solutions.

\section{IBSS ${ }^{\circledR}$ CAMD: a reverse engineering method for solvent design}

IBSS ${ }^{\circledR}$ CAMD is a novel methodology based on computer tools allowing the construction of chemical structures (pure compound or mixtures) satisfying a priori a set of target values for selected physicochemical properties. ${ }^{46}$ IBSS ${ }^{\circledR}$ CAMD can generate molecular structures "from scratch" starting either from conventional chemical groups or from archetypical biobased building blocks. The final solutions are constrained by the nature of the pre-selected chemical groups and the maximum number of groups allowed by the user in the molecules to be constructed. A candidate solvent is considered suitable for replacing hazardous solvents if its corresponding physicochemical properties are consistent with the desired specifications. Group contribution methods, which are known for their simplicity, accuracy and availability in CAMD tools ${ }^{47,48}$, are used for estimating molecular properties. ${ }^{49}$

The tailor-made molecular design problem is inherently multi-objective since several physicochemical properties must be satisfied at the same time for each molecular structure. Different molecular structures $(M S)$ are therefore ranked according to a GloPerf parameter that represents a weighted average performance. ${ }^{50}$ GloPerf is itself formulated as the average of $m$ individual performance factors $\operatorname{ProPerf}_{p}(\mathrm{MS}$, cond $_{j}$ ) each related to a single property prediction model, as given by:

$\operatorname{GloPerf}\left(M S, \operatorname{cond}_{j}\right)=\frac{\sum_{p=1}^{m} w_{p} * \operatorname{ProPerf}_{p}\left(P\left(M S, \operatorname{cond}_{j}\right)\right)}{\sum_{p=1}^{m} w_{p}}$

where $w_{p}$ are weighting factors that are selected by the user based on its knowledge of the property significance for the targeted application (see section 3). GloPerf equals unity in the ideal case, where all target properties are matched by a molecular structure and all $\operatorname{ProPerf}_{p}$ factors are equal to one. The ProPerf factor corresponding to a given property $P$ compares the property value $P$, predicted by the group contribution method, with the targeted value $V . P$ depends on the molecular structure (MS) and can also be a function of $j$ specific "conditions" ( cond $_{j}$ ) set by the user, such as for instance the temperature and/or pressure under which the experimental process is to be performed. The $\operatorname{ProPerf} p$ factors are calculated by using a Gaussian function defined by equation $(2)^{46,50 \text { : }}$

$\operatorname{ProPerf}_{P}\left(P\left(M S, \operatorname{cond}_{j}\right)\right)=\exp \left[-\left(\frac{V-P\left(M S, \text { cond }_{j}\right)}{\sigma}\right)^{2}\right]$

where the parameter $\sigma$ is used to define a "tolerance" margin around the target value. It determines the rate at which ProPerf $_{p}$ decreases when $P$ deviates from $V$. Fig. S1 shows an example corresponding to a property whose $P$ value is within a target range defined by two boundary values and thus two different $\sigma$ parameters $\left(\sigma_{L}\right.$ and $\sigma_{R}$ for the left and right domain boundaries respectively). Other examples corresponding to properties, whose $P$ values need either to be lower (higher) or equal to a given target value, are also shown in Fig. S1.

Altogether, the proposed methodology involves the following steps, illustrated in Scheme 1: (1) Initial problem definition and desired functionalities, (2) translation of functionalities into physicochemical properties and definition of target values, (3) selection of the predictive models for the 
physicochemical properties, (4) definition of the global performance function, (5) run IBSS ${ }^{\circledR}$ CAMD following one of two operating modes: molecular structure design or evaluation of existing solvents, and (6) candidate ranking according to GloPerf value and final choice of solvents to be tested in OPV devices.

\section{Solvent selection by IBSS ${ }^{\circledR}$ CAMD for donor- acceptor blends}

Solution-processed organic photovoltaic devices provide a particularly relevant case study, since the search for alternative solvents must include a large number of properties simultaneously. In a typical bulk heterojunction OPV device (Fig. $1 \mathrm{a})$, the main organic layer is composed of a blend of electrondonating (D) and electron-accepting (A) organic molecules sandwiched between two electrodes.3,39,51,52 The latter are generally consisting of indium tin oxide (ITO) and thin metal layers, modified by a few nanometers thick selective charge transport layers. The organic layer ensures the light absorption, exciton generation, exciton dissociation and charge carrier transport to the respective electrodes. The morphology of the organic layer is mainly determined during film casting, when both constituents separate into donor-rich and acceptor-rich domains, respectively. ${ }^{53,54}$ As exciton dissociation into free charge carriers occurs at the D/A interface, percolating nanometer-sized $D$ and $A$ domains are essential for efficient charge generation. ${ }^{54-56}$ The morphology of the active layer at the nanoscale is therefore a key factor underlying the performance of OPV devices. Although many studies have highlighted the existing correlations between various solvent properties and thin film morphology, it is not yet possible to fully anticipate the solvent properties that are best suited to process a given blend to its optimum. ${ }^{57-60}$ Extensive optimization of the blend composition and processing conditions is therefore generally required to achieve the highest power conversion efficiency for each particular donor/acceptor/solvent system. The chemical structures of the organic molecules used in this study are shown in Fig. 1b. Most relevant physico-chemical properties of both polymers are given in the ESI. For each D:A blend, IBSS ${ }^{\circledR}$ CAMD is used to identify candidate solvents following the methodology described above.

\section{Step 1: Initial problem definition and desired functionalities}

The list of desired properties that must be set in relation with the expected functionality of the solvents to be substituted may concern product issues as well as process issues. Typical examples are high solubility power, Newtonian fluid, low energy consumption, good capillarity, safety, and non-toxicity. To allow solution-based manufacturing of organic solar cells, it is essential that the alternative solvents are able to solubilize both donor and acceptor molecules and behave as Newtonian fluids, so that the active layer can be formed by standard printing techniques. The morphology of the active layer is strongly dependent on the kinetics of the film-forming and drying processes. Therefore, alternative solvents should yield a morphology matching closely the optimum configuration that leads to the highest PCE. Also, the solvents need to be in their liquid state at room temperature to avoid heating and allow energy efficient elaboration of thin films. Finally, the safety of solvents is obviously an important "functionality".

\section{Step 2: Translation of functionalities into physicochemical properties and definition of target values}

The physicochemical properties and the corresponding target values are defined so as to achieve the functionalities set above. The miscibility between alternative solvents and organic materials can be predicted by the Hansen solubility parameter theory (HSPs). Within this theoretical framework, the cohesive energy is divided into three intermolecular interactions which are: the non-polar interactions $\left(\delta_{D}\right)$, the polar dipole molecular interactions $\left(\delta_{P}\right)$, and the hydrogen bonds $\left(\delta_{H}\right){ }^{61}$ These parameters are generally represented by coordinates in a threedimensional space, the so-called Hansen space. The miscibility between a solvent and a solute can be estimated by the relative energy difference (RED) in Hansen space, defined by:

$R E D=R_{a} / R_{0}$

where

$R_{a}{ }^{2}=4\left(\delta_{D 1}-\delta_{D 2}\right)^{2}+\left(\delta_{P 1}-\delta_{P 2}\right)^{2}+\left(\delta_{H 1}-\delta_{H 2}\right)^{2}$

Here, $R_{a}$ is the "effective distance" between solvent (1) and solute (2) coordinates in Hansen space, and $R_{O}$ is the experimentally determined radius of the Hansen solubility sphere of the solute. Following the classical rule "like dissolves like" 61 , the affinity between a solvent and a solute increases with decreasing RED. A RED value below 1 indicates that the material is soluble to some extent: the lower the RED value the higher the solubility power should be.

The kinetics of film-drying primarily depend on the boiling point and vaporization enthalpy of the solvents during film printing. The boiling point is known to impact the polymer crystallinity (in case of semi-crystalline polymers such as P3HT) and the donor/acceptor average domain sizes.62,63 These parameters are hence critical for the final device performance.

The Newtonian fluid behaviour is related to moderate viscosity and density of solvents, two parameters that have to be taken into account for achieving high quality films (optimized thickness, homogeneity). A solvent that remains in the liquid state at room temperature needs to have a low melting point. Finally, the flash point, which determines the flammability of solvents and therefore the risks for explosion during the devices processing, should also be considered.

Based on the above, we have selected 11 target properties to be used by IBSS ${ }^{\circledR}$ CAMD to evaluate the performance of newly designed or existing solvent molecules, as summarized in Table 1. The target values of the properties were chosen by either taking into account preliminary experimental data or by using known properties of reference solvents. For instance, if a given property is expected to reach the same value as that of the solvent to be replaced (e.g. the same surface tension), the target value is set to the corresponding experimental value of the original solvent. For HSPs, preliminary experimental data 
are necessary to specify the required $\delta_{D}, \delta_{P} \delta_{H}$ values. Since the alternative solvents must solubilize both molecules of each blend, the HSPs of P3HT, PF2 and EH-IDTBR had first to be determined experimentally, while the HSPs of $\mathrm{PC}_{71} \mathrm{BM}$ were taken from the literature (Ref. 15). The corresponding data is given in the ESI. For $\mathrm{P} 3 \mathrm{HT}: \mathrm{PC}_{71} \mathrm{BM}$ blends, the overlap between Hansen spheres (or Hansen junction) of both molecules defines the space for solvents apt to solubilize both molecules. The Hansen junction "barycenter", which defines the coordinates of the solvent that should interact most efficiently with both materials, can be estimated by the HSPiP software ${ }^{64}$. For $\mathrm{P} 3 \mathrm{HT}: \mathrm{PC}_{71} \mathrm{BM}$, the junction barycenter values are 19.1, 5.0, 4.8 for $\delta_{D}, \delta_{P}$, and $\delta_{H}$, respectively. Therefore, the HSP target ranges for $\mathrm{P} 3 \mathrm{HT}: \mathrm{PC}_{71} \mathrm{BM}$ are set to $18<\delta_{D}<20,4<\delta_{P}<6$, and $3.5<\delta_{H}$ $<6$. Similarly, the junction values and corresponding HSP target ranges for the other three blends were determined experimentally and are summarized in Table 1 . To guarantee a good solubility of the blends in the selected solvent, it is also necessary that $R E D<1$ for each molecule-solvent pair. In our case, the rather high solubility radius $R_{0}$ of $\mathrm{PC}_{71} \mathrm{BM}$ leads the Hansen solubility spheres of P3HT and PF2 to be located fully inside the solubility sphere of $\mathrm{PC}_{71} \mathrm{BM}$ (Fig. 2). Therefore, the latter condition reduces to $R E D<1$ for the polymers only. The same holds for the blends with EH-IDTBR (see Fig. 2).

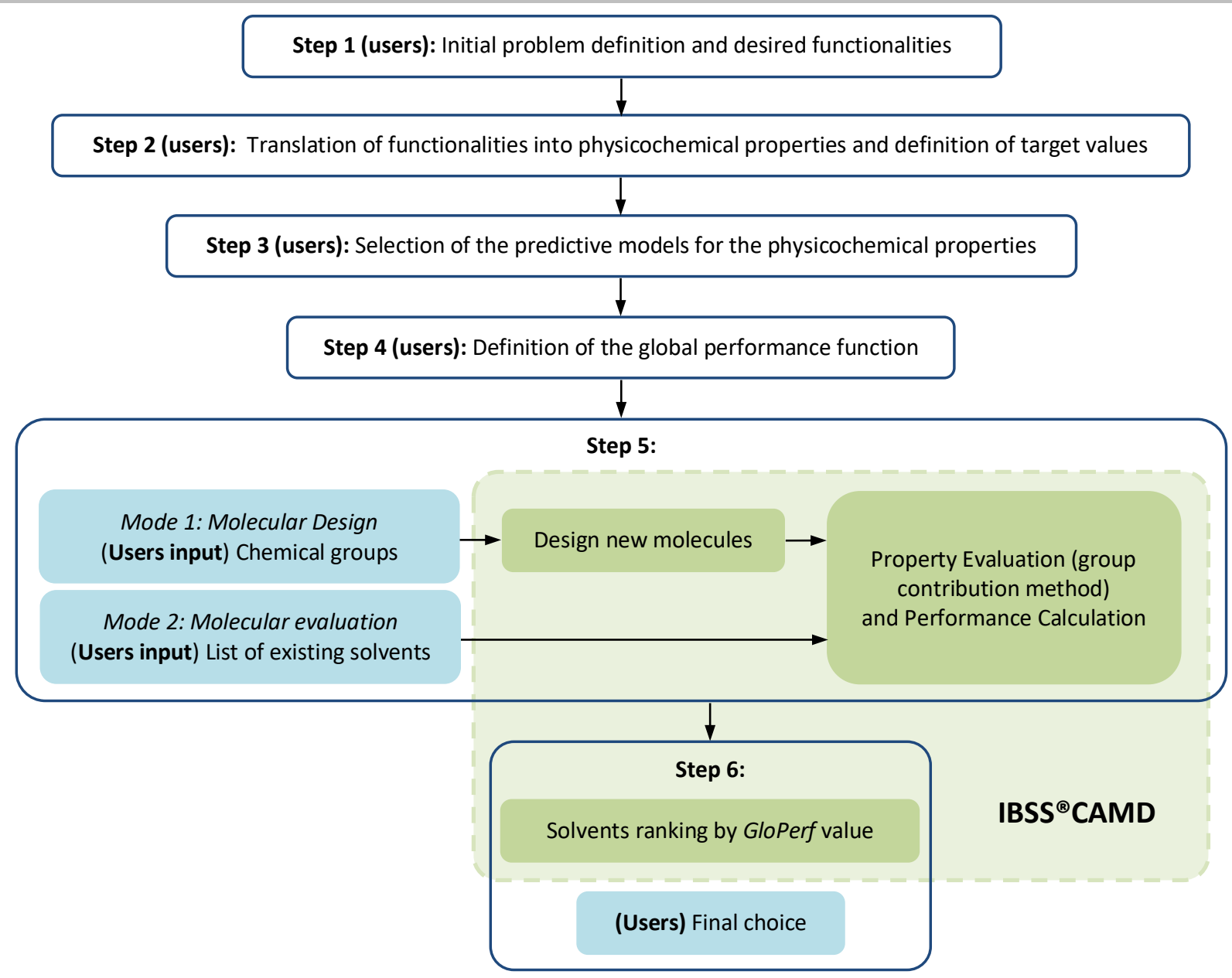

Scheme 1 Steps for IBSS ${ }^{\circledR}$ CAMD to design molecules and evaluate the performance of existing solvents. 
a

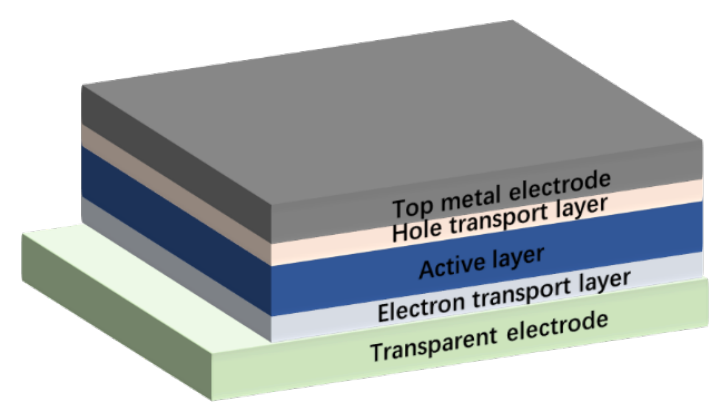

b

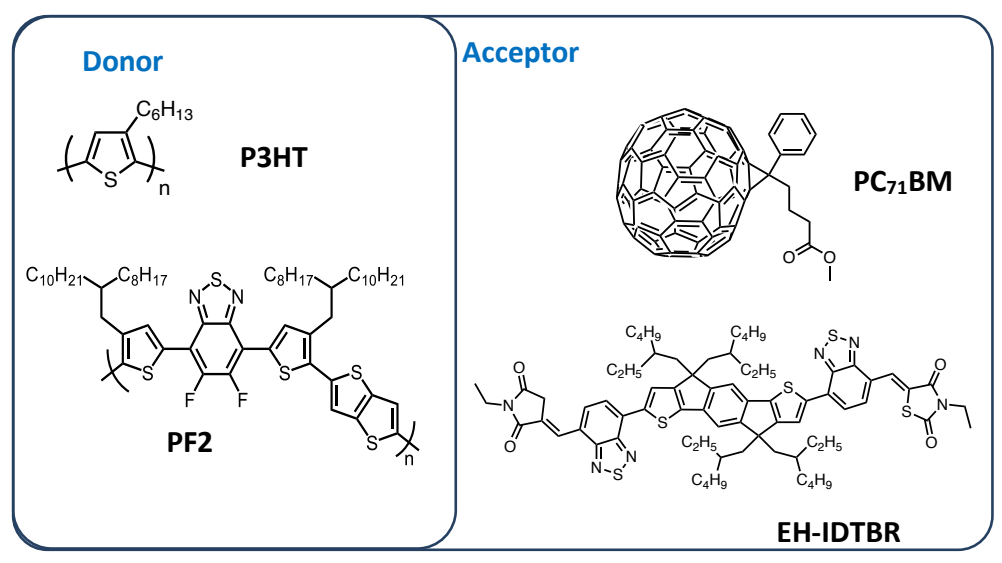

Fig. 1 (a) The typical structure of OPV device, and (b) the chemical structure of donors and acceptors.

For the solvent not to be classified as dangerous according to the National fire protection association (NFPA) ${ }^{65}$, its flash point needs to be larger than 296K. Similarly, a melting point lower than $283 \mathrm{~K}$ is requested to keep the solvent in its liquid state at typical processing temperatures.

For the properties $R_{a}$, boiling point, $\Delta H_{v a p}$, density, and viscosity, the target values have been defined by using the properties of a "reference" solvent. $O$-DCB is a good choice for P3HT:PC 11 BM, PF2:PC ${ }_{71} B M$ and PF2:EH-IDTBR, as it has led to the highest power conversion efficiencies. ${ }^{10,42,66}$ For similar reasons, $C B$ appears to be the best choice for P3HT:EH-IDTBR. ${ }^{6}$ The experimental database of the target properties for $0-\mathrm{DCB}$ and $\mathrm{CB}$ are summarized in Table S2. As the $R_{a}$ values between $o_{-}$ $\mathrm{DCB} / \mathrm{CB}$ and P3HT, as well as between $0-\mathrm{DCB}$ and PF2 are 2.83, 3.19 and 2.48 respectively, the target upper limit for $R_{a}$ was set to 3 for all the blends.

$O-D C B$ and $\mathrm{CB}$ have similar experimental boiling points, vaporization enthalpies, densities, and viscosities. We therefore chose the same target ranges for these properties. For the boiling point the target range is set to [ $373 \mathrm{~K}, 473 \mathrm{~K}$ ], which is in the same range than most halogenated solvents that have been used to prepare P3HT based devices. ${ }^{43,67}$ In addition, for the vaporization enthalpy, density, and viscosity, the target ranges are [35 kJ/mol, $55 \mathrm{~kJ} / \mathrm{mol}],\left[0.8 \mathrm{~g} / \mathrm{cm}^{3}, 1.5 \mathrm{~g} / \mathrm{cm}^{3}\right]$, and $[0.5$ $\mathrm{mPa} / \mathrm{s}, 1.5 \mathrm{mPa} / \mathrm{s}$ ] respectively, based on the database of $o-D C B$ and CB. All target values are summarized in Table 1.

\section{Step 3: Selection of the predictive models}

The values of a given property, $P$, are calculated using a property-estimation model and additional adjustable model parameters which depend on the property involved. The property-estimation model based on group contribution has the following form:

$P=\sum_{k \in G 1} n_{1 k} A_{k}+w \sum_{k \in G 2} n_{2 k} B_{k}+z \sum_{k \in G 3} n_{3 k} C_{k}$

where $G 1, G 2$ and $G 3$ are the sets of first, second and third order groups respectively, $A_{k}$ is the contribution of the first order group $k$ to the property $P$ that occurs $n_{1 k}$ times in the molecule, $B_{k}$ is the contribution of the second order group $k$ that occurs $n_{2 k}$ times and $C_{k}$ is the contribution of the third order group $k$ that occurs $n_{3 k}$ times. The $w$ and $z$ coefficients in equation 5 will be set to 1 or 0 depending on the availability of $B_{k}$ and $C_{k}$ in the CAMD database. For all properties, the $A_{k}, B_{k}$ and $C_{k}$ coefficients have been regressed from experimental data obtained over a large range of chemical families. ${ }^{49}$ The series of $A_{k}, B_{k}$ and $C_{k}$ coefficients for numerous physicochemical properties estimated by Marrero and Gani ${ }^{49}$ are used as a database by IBSS ${ }^{\circledR}$ CAMD. The universal constants of the models were determined by a regression scheme that can be found in Ref. 49.

For simple molecules, property $P$ can be estimated by using only the first term with $A_{k}$ values, which are known for all first order groups that are relevant to organic molecules. For more complex structures, $B_{k}$ and $C_{k}$ coefficients can improve the accuracy of the estimates allowing a better description of polyfunctional and polycyclic compounds and differentiation among isomers. The estimation of the boiling point of $\mathrm{N}$-phenyl-1,4-benzenediamine is given as an example in the ESI (Table S3).

\section{Step 4: Definition of the global performance function}

The $\sigma$ values (equation 2) are set by taking into account the uncertainty on the selected target values for each property (Table 1 ). The $w_{p}$ values (equation 1 ) are chosen by pondering the expected influence of the property on the performances of the devices. For instance, the solvent evaporation rate, which depends on both the boiling point and $\Delta H_{\text {vap }}$, influences the amount of residual solvents in deposited films as well as the degree of phase separation between donor and acceptor molecules during the film processing. We therefore set $w_{p}$ to 2 and 1 for the boiling point and $\Delta H_{\text {vap }}$ respectively, i.e. a cumulative weight of 3 on the solvent evaporation kinetics (Table 1). The high weight (8 in total) put on the solubility parameters ( $R_{a}, \mathrm{HSPs}$ and RED) is justified by the strong impact these properties have on the device elaboration process. 
(a)

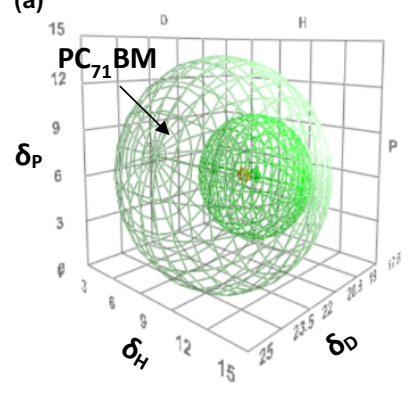

(b)

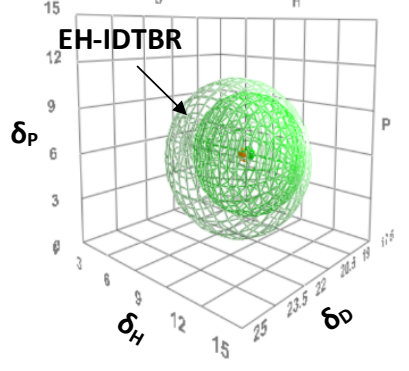

(c)

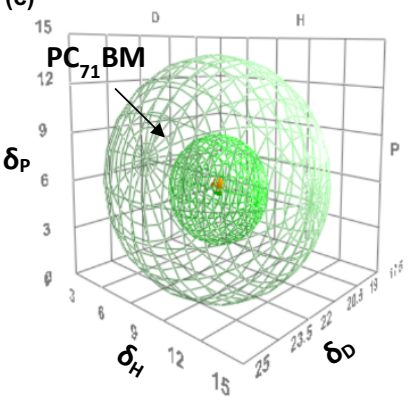

(d)

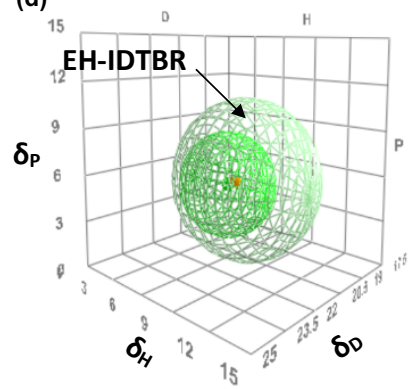

Fig. 2 (a) P3HT/PC 71 BM, (b) P3HT/EH-IDTBR, (c) PF2/PC ${ }_{71} B M$ and (d) PF2/EH-IDTBR HSPs in Hansen solubility space. (Dark green: polymer donors, light green: acceptors)

Table 1. The target properties, target value ranges and parameters of the performance functions.

\begin{tabular}{|c|c|c|c|c|c|}
\hline \multirow{2}{*}{ Functionalities } & \multirow{2}{*}{ Target properties } & \multirow{2}{*}{ Target values } & \multicolumn{3}{|c|}{ Parameters } \\
\hline & & & $w_{p}$ & $\sigma_{L}$ & $\sigma_{R}$ \\
\hline \multirow{5}{*}{ Solubility } & $\delta_{D}(\mathrm{MPa})^{1 / 2}$ & $\begin{array}{c}18<\delta_{D}<20^{[\mathrm{a}]} \\
17.5<\delta_{D}<19.5^{[\mathrm{b}]} \\
18.5<\delta_{D}<20.5^{[\mathrm{c}]} \\
18<\delta_{D}<20^{[\mathrm{d}]}\end{array}$ & 1 & 0.48 & 0.21 \\
\hline & $\delta_{P}(\mathrm{MPa})^{1 / 2}$ & $\begin{array}{c}4<\delta_{P}<6^{[\mathrm{a}]} \\
3.5<\delta_{P}<5.5^{[\mathrm{b}]} \\
3.4<\delta_{P}<5.4^{[\mathrm{c}]} \\
3.1<\delta_{P}<5.1^{[\mathrm{d}]}\end{array}$ & 1 & 0.56 & 0.48 \\
\hline & $\delta_{H}(\mathrm{MPa})^{1 / 2}$ & $\begin{array}{c}3.5<\delta_{H}<6^{[\mathrm{a}, \mathrm{b}]} \\
2.4<\delta_{H}<4.4^{[\mathrm{c}, \mathrm{d}]}\end{array}$ & 1 & 0.24 & 0.48 \\
\hline & $R_{a}(\mathrm{MPa})^{1 / 2}$ & $R_{a}<3$ & 3 & & 0.84 \\
\hline & $R E D$ & $<1$ & 2 & & 0.28 \\
\hline Film drying & Boiling point $\left(T_{b} / \mathrm{K}\right)$ & $373<\mathrm{BP}<473$ & 2 & 8.4 & 10.6 \\
\hline Film drying & Vaporization enthalpy ( $\left.\Delta \mathrm{H}_{\mathrm{vap}} \mathrm{kJ} / \mathrm{mol}\right)$ & $40<\Delta \mathrm{H}_{\mathrm{vap}}<55$ & 1 & 1.7 & 1.7 \\
\hline Film processing/ Newtonian fluid & Density $\left(\mathrm{kg} / \mathrm{m}^{3}\right)$ & $800<\rho<1500$ & 1 & 19.8 & 19.8 \\
\hline Film processing/ Newtonian fluid & Viscosity (mPa/s) & $0.5<\eta<1.5$ & 1 & 0.13 & 0.13 \\
\hline Safety & Flash Point $\left(T_{f} / \mathrm{K}\right)$ & $>296$ & 1 & 2.8 & \\
\hline Liquid state & Melting point $\left(T_{m} / \mathrm{K}\right)$ & $<283$ & 0.5 & & 4.2 \\
\hline
\end{tabular}

[a] P3HT:PC ${ }_{71} B M$ blends, [b] P3HT:EH-IDTBR blends, [c]PF2:PC ${ }_{71} B M$ blends and [d] PF2:EH-IDTBR blends. 


\section{Step 5: Molecular design parameters}

As mentioned above, IBSS ${ }^{\circledR}$ CAMD tool can be used either to design new molecules and optimize their structure to maximize GloPerf or to simply evaluate the GloPerf of existing solvents. Here we use the molecular design mode for $\mathrm{P} 3 \mathrm{HT}: \mathrm{PC}_{71} \mathrm{BM}$ and $\mathrm{PF} 2: \mathrm{PC}_{71} \mathrm{BM}$, and the second mode for $\mathrm{P} 3 \mathrm{HT}: \mathrm{PC}_{71} \mathrm{BM}, \mathrm{P} 3 \mathrm{HT}: \mathrm{EH}-$ IDTBR and PF2:EH-IDTBR. Using both methods on the same system ( $\mathrm{P} 3 \mathrm{HT}: \mathrm{PC}_{71} \mathrm{BM}$ ) allows us to highlight the benefits and drawbacks of each mode.

Molecular design: A genetic algorithm optimization method is implemented in IBSS ${ }^{\circledR}$ CAMD that allows the molecular structures to evolve gradually towards a GloPerf factor close to one. ${ }^{50}$ More specifically, new molecules have been built from a list of 238 chemical groups (Table S4) connected randomly by specifying possible positions and bond types (single, double or triple) for each group (some examples illustrating various possible combinations are given in Fig. S2). Halogen elements like $-\mathrm{Cl},-\mathrm{Br},-\mathrm{I}$ are discarded from the chemical group list to avoid a-priori toxic solvents. A total of 10102 molecular structures were generated for $\mathrm{P} 3 \mathrm{HT}: \mathrm{PC}_{71} \mathrm{BM}$ and 6720 molecular structures for $\mathrm{PF} 2: \mathrm{PC}_{71} \mathrm{BM}$, with their performances being evaluated and ranked following the GloPerf values.

Performance evaluation of existing solvents: In this mode, IBSS ${ }^{\circledR}$ CAMD is used to quickly evaluate the theoretical performance of a given list of existing solvents that have been chosen for a particular purpose. In the present case, the list consists of 138 solvents that have been previously reported to be sustainable in literature ${ }^{68}$, and includes bio-based solvents (see Table S5).

\section{Step 6: Candidate ranking and final choice}

For the designed solvents only those that have a CAS number and whose chemical synthesis is well established have been further investigated. Of these, the molecules with GloPerf above 0.5 (95 for $\mathrm{P} 3 \mathrm{HT}: \mathrm{PC}_{71} \mathrm{BM}$ and 39 for $\mathrm{PF} 2: \mathrm{PC}_{71} \mathrm{BM}$ ) are reported in the ESI (Table S6, S7, S8 and S9), along with their GloPerf and ProPerf $f_{P}$ values. Solvents with a GloPerf lower than 0.5 are unlikely to be appropriate for processing and have therefore been discarded. Likewise, for the list of sustainable solvents used in the evaluation mode, only those solvents with GloPerf above 0.5 were considered (Table S10, S11 and S12). Note however that solvents with similar GloPerf but different combinations of $\operatorname{ProPerf} f_{p}$ values may not be equally efficient in practice. It is therefore necessary to scrutinize the $\operatorname{ProPerf} f_{p}$ values for each solvent whose GloPerf $>0.5$, before selecting the final list of solvents that are to be tested for device elaboration. In this study, only those solvents whose ProPerf values on RED and $T_{b}$ (which are critical) are close to 1 have been further investigated.

Finally, properties that are out-of-reach to IBSS ${ }^{\circledR}$ CAMD have to be taken into account as well. The latter are related to cost issues, commercial availability, environmental impact and stability in air. Ultimately, in this study the candidate solvents selected for further investigations were all (1) greener (biobased if possible) than the solvent to be replaced according to the safety information data from the Globally harmonized system of classification and labelling of chemicals (GHS), (2) commercially available (CAS number available).

\section{Candidate solvents selection}

\section{- P3HT based blends}

Molecular design. Table 2 shows the list of seven candidate solvents for $\mathrm{P} 3 \mathrm{HT}: \mathrm{PC}_{71} \mathrm{BM}$ that were selected from the list of designed solvents (table S6), following the criteria described in the previous section. Among these, 4-ethynyltoluene (4-ET) can be considered as "ideal" solvent with a GloPerf value of 1 . The next best-ranked selected molecules are anisole $(A N)$ and 2methylanisole (2-MA) with GloPerf values of 0.997 and 0.946 . The $\operatorname{ProPerf}_{p}$ value of $P X$ is about 0.66 for $R_{a}$ suggesting that it is a less efficient solvent for $\mathrm{P} 3 \mathrm{HT}$ than 0 -DCB. Nevertheless, since its RED is lower than unity (0.75), it should still be able to dissolve $\mathrm{P} 3 \mathrm{HT}$ and $\mathrm{PC}_{71} \mathrm{BM}$ enough for processing OPV devices.

p-Cymene $(P C)$ and d-limonene $(L M)$ have still lower GloPerf values, with more properties matching poorly the target values (Table S6). For instance, the $\operatorname{ProPerf}_{p}$ for $R_{a}$ is particularly low. Nevertheless, since their RED values are still below 1 (0.89 and 0.94 for $P C$ and $L M$, respectively), and because their boiling points are high (close to $450 \mathrm{~K}$ ), it should be possible to dissolve $\mathrm{P} 3 \mathrm{HT}$ in these solvents at a higher processing temperature.

With a GloPerf close to 0.6, cyclopentyl methyl ether (CPME) appears still promising at first sight. However, due to its low flash point $\left(281 \mathrm{~K}, \operatorname{ProPerf}_{p} \approx 0\right)$ it cannot be retained for safety issues. We thus retained only $4-E T, A N, 2-M A, P X, P C$ and $L M$ as solvent candidates for the device elaboration.

Selected sustainable solvents. The best ranked candidate solvents from the sustainable solvent list for $\mathrm{P} 3 \mathrm{HT}: \mathrm{PC}_{71} \mathrm{BM}$ and P3HT:EH-IDTBR blends, respectively, and the corresponding full sets of ProPerf $f_{p}$ values are reported in Table S10 and Table S11. Further analysis of the individual $\operatorname{ProPerf}_{p}$ values given in Table S10 and Table S11, taking into account the criteria mentioned above, leads us to the following solvent selection, valid for both blends: $A N, P X, P C, L M$ and TPO

Note that $A N, P X, P C$, and $L M$ have also been identified as promising alternative solvents by the design mode, an agreement that underscores the effectiveness of IBSS@CAMD in designing solvents with target properties.

\section{- PF2 based blends}

Molecular design: Table 3 lists the only 4 out of 39 candidate solvents designed for PF2: $\mathrm{PC}_{71} \mathrm{BM}$, whose GloPerf is larger than 0.5 and accomplish the criteria mentioned in step 6 . This rather low number of alternatives is the outcome of the particularly small solubility radius of PF2 $\left(R_{o}=4.0\right)$, in comparison to P3HT $\left(R_{o}=4.7\right)$. The best solvent turns out to be $P X$ with a GloPerf of 0.931 and for which all ProPerf $f_{p}$ values are equal to unity except $\delta_{H}$ (ProPerf $f_{p} \approx 0$, see Table S12). For the remaining solvents 2 $M A, A N$ and $P C$, the RED values are 1.007, 1.029, and 1.026 respectively (shown in Table S8), indicating that they are located near the edge of the solubility sphere. In each case the ProPerf $P$ values for $R E D$ and $R_{a}$ are lower than one, anticipating 
a poor solubility for PF2 in these solvents (Table S12). This observation has been crosschecked by performing preliminary solubility measurements up to $120^{\circ} \mathrm{C}$ with a PF2 concentration of $4 \mathrm{mg} / \mathrm{ml}$ (Fig. S3). The results confirm that neither of these solvents allow to solubilize PF2 enough to be used for the elaboration of OPV devices. As a consequence, $P X$ turns out to be the only alternative designed solvent for $\mathrm{PF2}: \mathrm{PC}_{71} \mathrm{BM}$ blends.

Selected sustainable solvents. The 11 best ranked sustainable candidate solvents for PF2:EH-IDTBR and the corresponding full sets of $\operatorname{ProPerf}_{p}$ values are reported in Table
S10. Out of these, after taking into account the same criteria than above, $P X$ appears again as the only promising solvent candidate. Indeed, all solvents except $P X$ and Benzyl Benzoate (BBzo) exhibit poor solubility for PF2 (low ProPerf for RED and/or $R_{a}$ ). However, the boiling point of BBzo is too high $\left(\operatorname{ProPerf}_{p}\left(T_{b}\right) \approx 0\right)$ and would hinder drying of the thin film and lead to poor device performances. It is worth noting that $P X$ can be considered as a biosolvent, as it can be processed from biomass, unlike other xylenes which are obtained only from crude oil. ${ }^{68}$

Table 2. GloPerf and ProPerf $P$ values of the best ranked candidates for P3HT:PC ${ }_{71} \mathrm{BM}$ blend in both modes (Design mode: evaluation mode: $\star$ ).

\begin{tabular}{|c|c|c|c|c|c|c|c|c|c|}
\hline \multirow{2}{*}{ Candidates } & \multirow{2}{*}{ GloPerf } & \multirow{2}{*}{$\begin{array}{l}\text { IBSS }^{\circledR} \text { CAMD mode } \\
\text { (Design mode: } \\
\text { evaluation mode: } \star \text { ) }\end{array}$} & \multirow{2}{*}{ Biosolvents } & \multirow{2}{*}{$\begin{array}{l}\text { Safety information } \\
\text { (GHS label) }\end{array}$} & \multicolumn{5}{|c|}{ ProPerf } \\
\hline & & & & & $T_{b}$ & $T_{f}$ & $\Delta H_{\text {vap }}$ & $R_{a}$ & RED \\
\hline 4-Ethynyltoluene (4-ET) & 1.000 & $\bullet$ & & & 1.00 & 1.00 & 1.00 & 1.00 & 1.00 \\
\hline Anisole $(A N)$ & 0.997 & $\diamond / \star$ & & & 1.00 & 1.00 & 1.00 & 1.00 & 1.00 \\
\hline 2-Methyl anisole (2-MA) & 0.946 & $\diamond$ & & & 1.00 & 1.00 & 1.00 & 1.00 & 1.00 \\
\hline p-Xylene $(P X)$ & 0.853 & $\diamond / \star$ & $\mathscr{V}$ & & 1.00 & 1.00 & 1.00 & 0.66 & 1.00 \\
\hline $\mathrm{p}$-Cymene $(P C)$ & 0.628 & $\diamond / \star$ & $\mathscr{V}$ & & 1.00 & 1.00 & 1.00 & 0.13 & 1.00 \\
\hline Terpinolene (TPO) & 0.626 & $\star$ & & & 1.00 & 1.00 & 0.34 & 0.08 & 1.00 \\
\hline d-Limonene $(L M)$ & 0.598 & $\diamond / \star$ & $\mathscr{V}$ & & 1.00 & 1.00 & 1.00 & 0.06 & 1.00 \\
\hline $\begin{array}{l}\text { Cyclopentyl methyl } \\
\text { ether (CPME) }\end{array}$ & 0.592 & $\diamond / \star$ & & & 1.00 & 0.00 & 0.07 & 0.13 & 1.00 \\
\hline
\end{tabular}

[a] TCI AMERICA, https://www.chemblink.com/MSDS/MSDSFiles/766-97-2_TCI.pdf

[b] CDH, https://www.cdhfinechemical.com/

[c] ECHA, https://echa.europa.eu/

[d] http://www.cometchemical.com/MSDS/D-LimoneneEN.pdf

Table 3. GloPerf and ProPerf $f_{P}$ values of the best ranked solvent candidates for PF2:PC ${ }_{71} \mathrm{BM}$ blends by design mode.

\begin{tabular}{|c|c|c|c|c|c|c|c|c|}
\hline \multirow{2}{*}{ Candidates } & \multirow{2}{*}{ GloPerf } & \multirow{2}{*}{ Biosolvents } & \multirow{2}{*}{$\begin{array}{l}\text { Safety information } \\
\text { (GHS label) }\end{array}$} & \multicolumn{5}{|c|}{ ProPerf } \\
\hline & & & & $T_{b}$ & $T_{f}$ & $\Delta H_{\text {vap }}$ & $R_{a}$ & RED \\
\hline $\mathrm{p}$-Xylene $(P X)$ & 0.931 & $\mathscr{V}$ & & 1.00 & 1.00 & 1.00 & 1.00 & 1.00 \\
\hline 2-Methyl anisole (2-MA) & 0.770 & & & 1.00 & 1.00 & 1.00 & 0.22 & 1.00 \\
\hline Anisole $(A N)$ & 0.724 & $\mathscr{V}$ & & 1.00 & 1.00 & 1.00 & 0.17 & 0.99 \\
\hline p-Cymene $(P C)$ & 0.693 & $\mathscr{V}$ & & 1.00 & 1.00 & 1.00 & 0.18 & 0.99 \\
\hline
\end{tabular}


The above results allow us to point out some benefits and drawbacks of both solvent selection modes. The molecular design mode leads to a large number of solvent candidates matching closely the target properties, but may require further extensive experimental investigations to evaluate unpredictable properties such as toxicity, synthesis routes, costs, etc. Also, the limited number of chemical building blocks does not allow boundless exploration of molecular structures. For instance, TPO is not included in the design list for P3HT blends, while it is in the list of sustainable solvents. On the other hand, applying IBSS ${ }^{\circledR}$ CAMD to a finite list of existing solvents is quicker (processing time $<30 \mathrm{~min}$ on a standard personal computer) than molecular design mode (processing time depends on the number of chemical groups and can vary between a few hours to a few days) but may miss promising solvents. In our case, 4-ET and 2-MA have been identified by the design mode while they were not included in the sustainable solvent list of Ref. 68 despite the fact that they have being recognized as healthy and environmentally friendly. ${ }^{69-71}$

\section{Photovoltaic Performance}

We have fabricated OPV devices using each of the previously selected alternative solvents. Reference devices processed from $o-D C B / C B$ solutions were also investigated. The device structure is illustrated in Fig. 1a. It includes ITO as transparent electrode, a thin layer of $\mathrm{ZnO}$ nano-particles as electron transporting layer, $\mathrm{MoO}_{3}$ as hole transporting layer and $\mathrm{Ag}$ as top electrode. Additional experimental details on the device elaboration and characterization are given in the experimental part.

P3HT based devices: the active layer of $\mathrm{P} 3 \mathrm{HT}: \mathrm{PC}_{71} \mathrm{BM}$ devices was composed of a blend of $\mathrm{P} 3 \mathrm{HT}$ and $\mathrm{PC}_{71} \mathrm{BM}$ with a 1:0.7 weight ratio. The solutions were annealed and stirred overnight at various processing temperatures in nitrogen ambient (see Table 4). A slightly higher processing temperature was adopted for the poorer solvents $P C, T P O$ and $L M$. The thin films were fabricated by spin-coating onto substrates previously heated at the same temperature. After deposition, the films were further annealed at $130^{\circ} \mathrm{C}$ for $15 \mathrm{~min}$ under an inert atmosphere. The $(\mathrm{J}-\mathrm{V})$ characteristics of the devices under darkness and under standard illumination conditions (AM1.5G) are reported in Fig. 3 and Fig. S4. The corresponding photovoltaic parameters are summarized in Table 4 and Table S13. Note that the processing conditions were kept identical to the reference devices, except for the eventual introduction of diphenyl ether (DPE) as solvent additive (see below) and the slight increase in processing temperature for $P C$ and $L M . .^{72} \mathrm{It}$ is important to note at this point that IBSS ${ }^{\circledR}$ CAMD is not expected to fully predict photovoltaic performances but only to identify molecules that have the potential to be used efficiently for device elaboration. Properties such as nanoscale morphology or degree of phase separation of donor/acceptor blends, that are extremely sensitive to the film forming kinetics, are beyond reach for IBSS ${ }^{\circledR}$ CAMD.
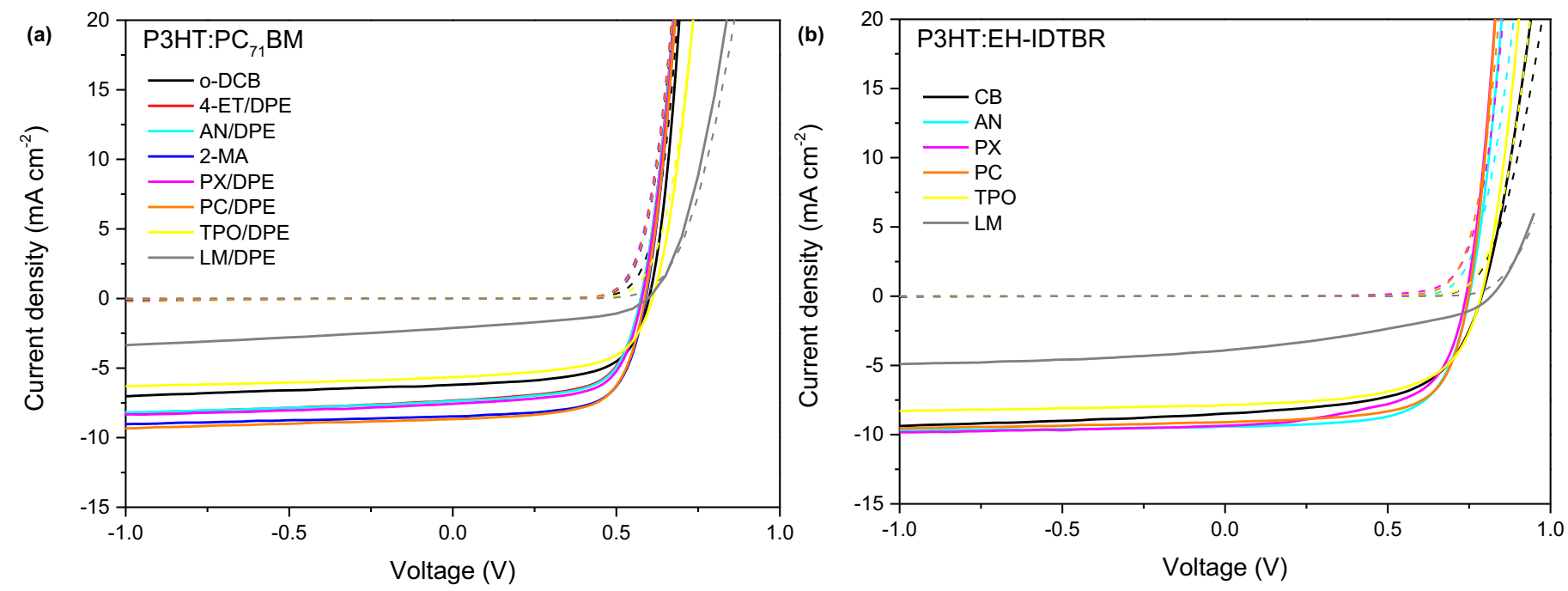

Fig. 3. The (J-V) curves of (a) P3HT:PC 71 BM OPVs and (b) P3HT:EH-IDTBR OPVs processed from various solvents. (Solid line: devices were measured under illumination, dash line: devices were measured under darkness) 
Table 4. Photovoltaic device parameters of $\mathrm{P} 3 \mathrm{HT}: \mathrm{PC}_{71} \mathrm{BM}$ and $\mathrm{P} 3 \mathrm{HT}$ :EH-IDTBR based devices fabricated from various solvents.

\begin{tabular}{|c|c|c|c|c|c|c|c|}
\hline Materials & $\begin{array}{c}\text { Processing } \\
\text { solvents }\end{array}$ & $\begin{array}{c}\text { Processing } \\
\text { temperature }\left[{ }^{\circ} \mathrm{C}\right]\end{array}$ & $\mathrm{V}_{\mathrm{oc}}[\mathrm{mV}]$ & $\mathrm{J}_{\mathrm{sc}}\left[\mathrm{mA} \mathrm{cm}^{-2}\right]$ & $\mathrm{FF}[\%]$ & PCE [\%] & Thickness [nm] \\
\hline \multirow{8}{*}{ P3HT:PC ${ }_{71} \mathrm{BM}$} & $o-\mathrm{DCB}$ & 80 & $594 \pm 5$ & $6.3 \pm 0.1$ & $59 \pm 3$ & $2.3 \pm 0.2$ & $\sim 100$ \\
\hline & 4-ET/DPE & 100 & $575 \pm 3$ & $7.2 \pm 0.2$ & $61 \pm 2$ & $2.6 \pm 0.1$ & $\sim 110$ \\
\hline & AN/DPE & 100 & $575 \pm 3$ & $7.4 \pm 0.1$ & $63 \pm 1$ & $2.7 \pm 0.1$ & $\sim 140$ \\
\hline & $2-M A$ & 100 & $587 \pm 2$ & $8.3 \pm 0.1$ & $64 \pm 1$ & $3.1 \pm 0.2$ & $\sim 100$ \\
\hline & $P X / D P E$ & 100 & $577 \pm 2$ & $7.5 \pm 0.1$ & $64 \pm 1$ & $2.7 \pm 0.2$ & $\sim 130$ \\
\hline & $P C / D P E$ & 115 & $585 \pm 6$ & $8.5 \pm 0.2$ & $65 \pm 1$ & $3.3 \pm 0.1$ & $\sim 120$ \\
\hline & TPO/DPE & 115 & $606 \pm 6$ & $5.4 \pm 0.2$ & $57 \pm 1$ & $1.9 \pm 0.1$ & $\sim 90$ \\
\hline & $L M / D P E$ & 115 & $669 \pm 7$ & $3.3 \pm 0.2$ & $43 \pm 3$ & $1.0 \pm 0.1$ & $\sim 100$ \\
\hline \multirow{7}{*}{ P3HT:EH-IDTBR } & $\mathrm{CB}$ & 80 & $780 \pm 6$ & $8.1 \pm 0.4$ & $53 \pm 4$ & $3.5 \pm 0.4$ & $\sim 120$ \\
\hline & $A N$ & 80 & $752 \pm 7$ & $9.2 \pm 0.3$ & $66 \pm 2$ & $4.6 \pm 0.1$ & $\sim 140$ \\
\hline & $P X$ & 80 & $742 \pm 4$ & $8.91 \pm 0.3$ & $57 \pm 2$ & $3.8 \pm 0.2$ & 150 \\
\hline & & & & & & & \\
\hline & $P C$ & 100 & $749 \pm 8$ & $8.9 \pm 0.2$ & $65 \pm 1$ & $4.4 \pm 0.3$ & $\sim 120$ \\
\hline & TPO & 100 & $787 \pm 2$ & $7.8 \pm 0.1$ & $59 \pm 1$ & $3.6 \pm 0.1$ & $\sim 100$ \\
\hline & $L M$ & 100 & $816 \pm 4$ & $3.6 \pm 0.3$ & $36 \pm 1$ & $1.0 \pm 0.2$ & $\sim 100$ \\
\hline
\end{tabular}

The devices processed from 2-MA solutions gave the best performance, and even out-performed slightly $o$-DCB-based reference devices. On the other hand, the devices fabricated from 4-ET, $A N, P X, P C$ and TPO solutions led to low current densities and poor power conversion efficiencies (see Fig. S4). Devices processed from pure $L M$ solutions were not operational. Since a pronounced phase separation between both constituents of the blend is a possible cause for the observed poor performances, ${ }^{58}$ we fabricated additional devices by adding 3\% of DPE (a non-halogenated processing additive) to the polymer solution. It is indeed well established that DPE, with its high boiling temperature and good solvent properties for $\mathrm{PC}_{71} \mathrm{BM}$, delays the formation of $\mathrm{PC}_{71} \mathrm{BM}$ aggregates during film casting ${ }^{10,52}$, improving the thin film morphology. ${ }^{10,52}$ As shown in Fig. 3, devices processed from 4$E T, A N, P X$ and $P C$, with $3 \%$ DPE perform significantly better, leading to a PCE ( 3\%) slightly higher than the average PCE reported for OPVs processed from $O$-DCB solutions. ${ }^{40,73}$ Using $T P O$ and $L M$ as alternative solvents led however to low performances, even after the introduction of DPE. This is in line with the lower GloPerf factors of TPO and $L M$ and suggests that solvents with still lower GloPerf values are likely to be inefficient for processing $\mathrm{P} 3 \mathrm{HT}: \mathrm{PC}_{71} \mathrm{BM}$ devices. It is worth to note that
IBSS ${ }^{\circledR}$ CAMD could as well be used to design and evaluate alternative solvents to be employed as additives rather than host solvents, provided the target properties of the additive are well established. ${ }^{67}$ We have not included this approach at this stage.

The current-voltage curves of P3HT:EH-IDTBR devices and the extracted physical parameters are depicted in Fig. 3 and summarized in Table 4. Good photovoltaic performances could be achieved with all the selected solvents except $L M$. The poor performances of devices processed from $L M$ are in-line with its low GloPerf value. The highest PCE values are obtained for $A N$ and $P C$-based devices with $4.6 \%$ and $4.4 \%$, respectively. Also in this case, the solvent-to-solvent variations can be attributed to incomplete optimization of the processing conditions. Clarifying the origin of the performance fluctuations would need more indepth investigations that lie beyond the scope of this paper. Nevertheless, the average PCE achieved with P3HT:EH-IDTBR processed with $A N$ is of the same order of magnitude than the values reported in literature. It is noteworthy that for none of the solvents a processing additive was needed to achieve high efficiencies, in strong contrast with the behaviour of $\mathrm{P} 3 \mathrm{HT}: \mathrm{PC}_{71} \mathrm{BM}$ devices. This difference is possibly linked to the 
smaller $R_{a}$ and $R E D$ values of EH-IDTBR, as compared to $\mathrm{PC}_{71} \mathrm{BM}$ (Table S14).

PF2 based devices: the active layer of PF2:PC ${ }_{71} \mathrm{BM}$ devices was composed of a blend of PF2 and $P C_{71} B M$ with a 1:1.5 weight ratio. ${ }^{42}$ The blend films were processed either from hot $O-D C B$, $P X$ or $P X / D P E$ solutions $\left(\approx 100^{\circ} \mathrm{C}\right)$ and spin-coated onto substrates previously heated at the same temperature. The photovoltaic properties are shown in Fig. 4a and are summarized in Table 5.

The devices processed from pure $P X$ led to a low PCE. Again, adding $3 \%$ of DPE significantly improved the efficiency, leading to an average PCE of $9.1 \%$ (maximum PCE: $9.47 \%$ ), which is close to the performance of devices processed from $o$-DCB. The slightly lower $J_{s c}$ for $P X$ processed devices may be attributed to the slightly lower thickness of the active-layer (Table 5). The high FF (max. 76.5\%) points out excellent charge carrier extraction. It is worth to point out that the devices processed from $P X / D P E$ could be manufactured at a lower temperature $\left(70^{\circ} \mathrm{C}\right)$ than for $0-\mathrm{DCB}\left(100^{\circ} \mathrm{C}\right)(\mathrm{Fig} . \mathrm{S} 5, \mathrm{~S} 6$ and Table S15). This is possibly the consequence of the lower viscosity of $P X$ with respect to $o$-DCB (Table S9) and should facilitate the production of large area modules and reduce manufacturing costs. ${ }^{42}$ The latter allows to achieve the same layer thickness with similar spin-coating conditions but at lower temperature than with the reference solvent. We note that the process was kept as close as possible to the deposition parameters known as optimal for $o$-DCB. Full optimization of the elaboration procedure based on $P X$ lies however beyond the scope of this article. The currentvoltage curves and corresponding photovoltaic parameters of PF2:EH-IDTBR devices are shown in Fig. $4 \mathrm{~b}$ and Table 5. The average $P C E$ equals $8.0 \%$ when processed from $P X$ solutions, exceeding the PCE of devices processed from 0 -DCB (7.29\%). These results corroborate the good global performance of $P X$ as alternative solvent determined by IBSS ${ }^{\circledR} \mathrm{CAMD}$. As for $\mathrm{P} 3 \mathrm{HT}$ :EHIDTBR, the devices could be fabricated without additive (Table S14).
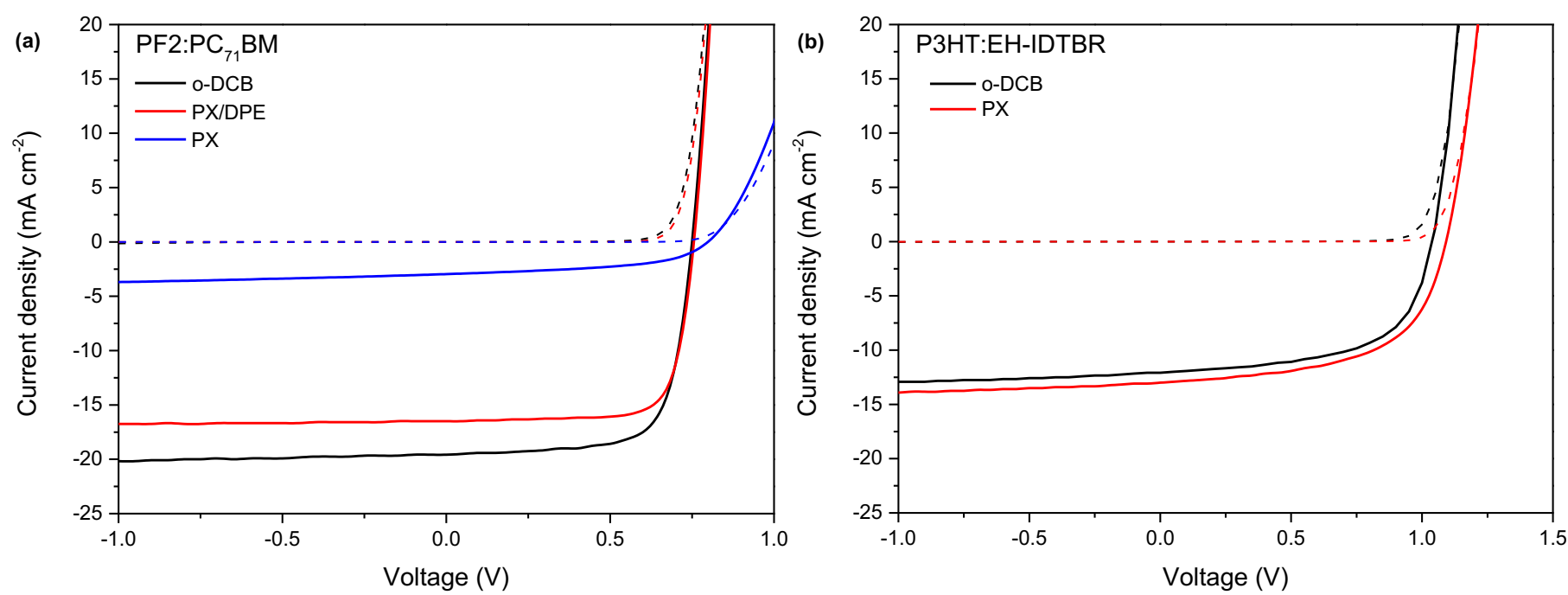

Fig. 4. (a) The (J-V) curves of P3HT:PC 71 BM OPVS processed from various solvents, and (b) The (J-V) curves of PF2:EH-IDTBR based OPVs processed from $o-D C B$ and PX. (Solid line: devices were measured under illumination, dash line: devices were measured under darkness)

Table 5. The corresponding photovoltaic device parameters of PF2 based devices fabricated from various solvents.

\begin{tabular}{|c|c|c|c|c|c|c|c|}
\hline Materials & $\begin{array}{l}\text { Processing } \\
\text { solvents }\end{array}$ & $\begin{array}{c}\text { Processing } \\
\text { temperature }\left[{ }^{\circ} \mathrm{C}\right]\end{array}$ & $\mathrm{V}_{\mathrm{oc}}[\mathrm{mV}]$ & $\mathrm{J}_{\mathrm{sc}}\left[\mathrm{mA} \mathrm{cm} \mathrm{cm}^{-2}\right]$ & FF [\%] & PCE [\%] & Thickness [nm] \\
\hline \multirow{3}{*}{$\mathrm{PF} 2: \mathrm{PC}_{71} \mathrm{BM}$} & $o-\mathrm{DCB}$ & $100^{\circ} \mathrm{C}$ & $754 \pm 5$ & $17.9 \pm 1.3$ & $73 \pm 1$ & $9.8 \pm 0.7$ & $\sim 160$ \\
\hline & $P X / D P E$ & $100^{\circ} \mathrm{C}$ & $753 \pm 3$ & $15.9 \pm 0.6$ & $75 \pm 1$ & $9.1 \pm 0.4$ & $\sim 130$ \\
\hline & $P X$ & $100^{\circ} \mathrm{C}$ & $801 \pm 5$ & $3.0 \pm 0.3$ & $50 \pm 4$ & $1.2 \pm 0.2$ & $\sim 130$ \\
\hline \multirow{2}{*}{ PF2:EH-IDTBR } & $o-D C B$ & $100^{\circ} \mathrm{C}$ & $1040 \pm 5$ & $12.9 \pm 0.2$ & $58 \pm 1$ & $7.3 \pm 0.2$ & $\sim 150$ \\
\hline & $P X$ & $100^{\circ} \mathrm{C}$ & $1070 \pm 3$ & $13.2 \pm 0.1$ & $56 \pm 1$ & $8.0 \pm 0.1$ & $\sim 130$ \\
\hline
\end{tabular}




\section{Conclusions}

A systematic reverse engineering methodology applied via IBSS ${ }^{\circledR}$ CAMD tool has been successfully used to design and select alternative solvents for OPV devices, in replacement of toxic solvents. The method required the identification of the solvent functionalities, their translation into target physicochemical properties, and for the setting of target property values. By solving a multi-objective optimization problem with a computer assisted molecular design tool (IBSS ${ }^{\circledR}$ CAMD), the alternative solvents were ranked according to a global performance value, which evaluates the matching of their multiple physicochemical properties with a set of target values. In our cases, eleven target properties were considered as important for achieving highperformance OPV devices. By exploring the diversity of molecular structures, the reverse engineering approach greatly expands the list of candidate solvents and can give rise to solvents that exhibit better performances. The method was applied successfully to four bulk heterojunctions solar cells using $\mathrm{P} 3 \mathrm{HT}$ as electron donor and either $\mathrm{PC}_{71} \mathrm{BM}$ or EH-IDTBR as electron acceptor, or $\mathrm{PF} 2$ as electron donor and $\mathrm{PC}_{71} \mathrm{BM}$ or $\mathrm{EH}-$ IDTBR as electron acceptor. For $\mathrm{P} 3 \mathrm{HT}: \mathrm{PC}_{71} \mathrm{BM}$, seven alternative solvents were found suitable to be used for OPV device processing, with the highest average PCE of 3.3\% obtained by using $p$-cymene/DPE solutions. For P3HT:EH-IDTBR, four alternative solvents could be selected from the sustainable solvent list, with anisole giving rise to the highest average PCE of $4.6 \%$. Importantly, all of the alternative solvents, with the exception of 2-MA, can be bio-sourced and are therefore of particular interest for future industrial up-scaling. For PF2:PC ${ }_{71}$ BM and PF2:EH-IDTBR blends, $p$-xylene, a solvent that can be produced from biological sources, has been identified as efficient alternative solvent. For PF2: $\mathrm{PC}_{71} \mathrm{BM}$, the $p$-xylene/DPE solutions yielded performances close to those of reference devices, while for PF2:EH-IDTBR a PCE of 8.0\%, larger than that of the reference device (7.3\%), could beachieved using $P X$ without additive. All the alternative solvents mentioned above are greener than common halogenated solvents and commercially available.

Our results show that the reverse engineering methodology provides an efficient way to find alternative solvents for the processing of organic photovoltaic blends. While this study considered only blends of polymers with small molecules, the method should be equally effective on polymer:polymer blends or on blends of small molecules. Overall, the method should make the selection of green solvents for future new photovoltaic materials less empirical and avoid relying primarily on a time-consuming trial and error approach.

\section{Experimental Section}

Materials: $\mathrm{P} 3 \mathrm{HT}$ was purchased from Solaris Chem Inc., $\mathrm{PC}_{71} \mathrm{BM}$ was from Solenne. Fluorinated polymer PF2 were prepared as described in the literature. ${ }^{1}$ The processing solvents: $1,2-$ dichlorobenzene (o-DCB), 4-ethynyltoluene, Anisole, 2-methyl anisole, $p$-xylene, $p$-cymene, and d-limonene, were purchased from Sigma Aldrich. A ZnO nanoparticle dispersion ( $\mathrm{N}-10)$ was purchased from Avantama. ITO coated Glass substrates were purchased from Luminescence Technology (LumTech) Corporation.

Fabrication of inverted OPV devices: ITO coated glass substrates were cleaned in ultrasonic bath of deionized water, acetone and 2-propanol at $45^{\circ} \mathrm{C}$ for 15 minutes for each step. Then, they were dried by nitrogen and were treated in a UV/Ozone oven to remove residual organic contaminants. A zinc oxide film ( $\mathrm{ZnO}$ ) was prepared on the washed ITO substrate by a spin-coating method (4000 rpm, 10nm). The as-deposited $\mathrm{ZnO}$ was heated on a hot plate at $110^{\circ} \mathrm{C}$ for $12 \mathrm{~min}$ in air. The photoactive layer was prepared from different solutions containing $\mathrm{P} 3 \mathrm{HT}: \mathrm{PC}_{71} \mathrm{BM}$ blends with a concentration of 18 $\mathrm{mg} / \mathrm{ml}$ of P3HT. The ratio of donor and acceptor is 1:0.7. The solution was spin-coated onto the $\mathrm{ZnO} / \mathrm{ITO}$ substrates, and the resulting films were annealed at $130^{\circ} \mathrm{C}$ for $15 \mathrm{~min}$ under a nitrogen atmosphere. The active layer of $\mathrm{PF} 2: \mathrm{PC}_{71} \mathrm{BM}$ blend were elaborated from solutions at a weight ratio of 1:1.5 and a total concentration of $13 \mathrm{mg} / \mathrm{mL}$. For the PF2:EH-IDTBR based devices, the active layer was composed of PF2:EH-IDTBR blends with a 1:1 weight ratio from hot 1,2-dichlorobenzene and $p$ xylene solutions that were annealed and stirred overnight at $100^{\circ} \mathrm{C}$ in nitrogen ambient. The overall concentration of PF2:EHIDTBR blends is $8 \mathrm{mg} / \mathrm{ml}$. The $7 \mathrm{~nm}$ thin $\mathrm{MoO}_{3}$ and $120 \mathrm{~nm}$ thin Ag layers were thermally evaporated in vacuum (Pressure $\approx$ $1 \times 10^{-6} \mathrm{mbar}$ ).

OPV measurements: The JV curves of the OPVs were measured under an AM $1.5 \mathrm{G}-100 \mathrm{~mW} / \mathrm{cm}^{2}$ solar simulator using a LabView-controlled Keithley $2400 \mathrm{SMU}$. A shadow mask was used to set the illuminated area to $12 \mathrm{~mm}^{2}$ (slightly lower than the actual device area). The JV results are from the averages of 20 devices.

Thickness measurement : The film thickness was measured by a DektakXT stylus profiler at 6 different positions after scratching the film with a diamond scriber.

\section{Conflicts of interest}

There are no conflicts to declare.

\section{Acknowledgements}

The work has been supported by the Centre National de la Recherche Scientifique (PHOTOSOLV project) and has received funding from the INTERREG Upper Rhine European Regional Development Fund, the Ministries for Research of BadenWürttemberg, Rheinland-Pfalz, and from the Region Grand Est in the framework of the project no. 3.10 (PROOF). J. Wang acknowledges financial support from the China Scholarship Council (CSC).

The authors thank Nicolas Zimmermann for technical support. 


\section{Notes and reference}

1

L. Meng, Y. Zhang, X. Wan, C. Li, X. Zhang, Y. Wang, X. Ke, Z. Xiao, L. Ding, R. Xia, H. L. Yip, Y. Cao and Y. Chen, Science (80-. )., 2018, 361, 1094-1098. Q. Liu, Y. Jiang, K. Jin, J. Qin, J. Xu, W. Li, J. Xiong, J. Liu, Z. Xiao, K. Sun, S. Yang, X. Zhang and L. Ding, Sci. Bull., 2020, 65, 272-275. Y. Cui, H. Yao, J. Zhang, T. Zhang, Y. Wang, L. Hong, K. Xian, B. Xu, S. Zhang, J. Peng, Z. Wei, F. Gao and J. Hou, Nat. Commun., 2019, 10, 2515. S. Oh, C. E. Song, T. Lee, A. Cho, H. K. Lee, J. C. Lee, S. J. Moon, E. Lim, S. K. Lee and W. S. Shin, J. Mater. Chem. A, 2019, 7, 22044-22053. E. Destouesse, S. Chambon, S. Courtel, L. Hirsch and G. Wantz, ACS Appl. Mater. Interfaces, 2015, 7, 24663-24669. M. Karakawa, K. Suzuki, T. Kuwabara, T. Taima, K. Nagai, M. Nakano, T. Yamaguchi and K. Takahashi, Org. Electron., 2020, 76, 105448.
Y. II Lee, J. H. Youn, M. S. Ryu, J. Kim, H. T. Moon and J. Jang, Org. Electron., 2011, 12, 353-357.

J. H. Yun, H. Ahn, P. Lee, M. J. Ko and H. J. Son, Macromolecules, 2017, 50, 7567-7576.

Y. Zheng, G. Wang, D. Huang, J. Kong, T. H. Goh, W. Huang, J. Yu and A. D. Taylor, Sol. RRL, 2018, 2, 1700144.

T. H. Lee, S. Y. Park, B. Walker, S. J. Ko, J. Heo, H. Y. Woo, H. Choi and J. Y. Kim, RSC Adv., 2017, 7, 7476-7482.

X. Che, Y. Li, Y. Qu and S. R. Forrest, Nat. Energy, 2018, 3, 422-427.

W. Zhao, S. Zhang, Y. Zhang, S. Li, X. Liu, C. He, Z. Zheng and J. Hou, Adv. Mater., 2018, 30, 1704387.

O. A. Ibraikulov, J. Wang, N. Kamatham, B. Heinrich, S. Méry, M. Kohlstädt, U. Würfel, S. Ferry, N. Leclerc, T. Heiser and P. Lévêque, Sol. RRL, 2019, 3, 1900273.

L. Hong, H. Yao, Z. Wu, Y. Cui, T. Zhang, Y. Xu, R. Yu, Q. Liao, B. Gao, K. Xian, H. Y. Woo, Z. Ge and J. Hou, Adv. Mater., 2019, 31, 1903441.

W. Shen, M. Xiao, J. Tang, X. Wang, W. Chen, R. Yang, X. Bao, Y. Wang, J. Jiao, L. Huang, J. Liu, W. Wang and L. A. Belfiore, RSC Adv., 2015, 5, 47451-47457.

K. S. Chen, H. L. Yip, C. W. Schlenker, D. S. Ginger and A. K. Y. Jen, Org. Electron., 2012, 13, 2870-2878.

W. Cai, P. Liu, Y. Jin, Q. Xue, F. Liu, T. P. Russell, F. Huang, H. L. Yip and Y. Cao, Adv. Sci., 2015, 2, 1500095.

B. Meng, Y. Fu, Z. Xie, J. Liu and L. Wang, Polym. Chem., 2015, 6, 805-812.

L. Ye, Y. Xiong, Q. Zhang, S. Li, C. Wang, Z. Jiang, J. Hou, W. You and H. Ade, Adv. Mater., 2018, 30, 1705485.

K. Zhang, Z. Chen, A. Armin, S. Dong, R. Xia, H. L. Yip, S. Shoaee, F. Huang and Y. Cao, Sol. RRL, 2018, 2, 1700169. M. Rammal, P. Leveque, G. Schlatter, N. Leclerc and A. Hebtraud, Mater. Chem. Front., 2020, 4, 2904.

C. Xie, T. Heumüller, W. Gruber, X. Tang, A. Classen, I. Schuldes, M. Bidwell, A. Späth, R. H. Fink, T. Unruh, I. Mcculloch, N. Li and C. J. Brabec, Nat. Commun., 2018, 9, 5335.
J. François and L. Rafael, Bio-Based Solvents, Wiley \& Sons, Ltd., 2017.

L. Zheng, J. Xu, Y. Feng, H. Shan, G. Fang and Z. X. Xu, J. Mater. Chem. C, 2018, 6, 11471-11478.

Y. Wang, C. Yan, S. Y. Cheng, Z. Q. Xu, X. Sun, Y. H. Xu, J. J. Chen, Z. Jiang, K. Liang and Z. S. Feng, Adv. Funct. Mater., 2019, 29, 1902579.

J. Hong, C. Wang, H. Cha, H. N. Kim, Y. Kim, C. E. Park, T. K. An, S. K. Kwon and Y. H. Kim, Chem. - A Eur. J., 2019, 25, 649-656.

J. Lee, S. J. Ko, H. Lee, J. Huang, Z. Zhu, M. Seifrid, J. Vollbrecht, V. V. Brus, A. Karki, H. Wang, K. Cho, T. Q. Nguyen and G. C. Bazan, ACS Energy Lett., 2019, 4, 14011409.

J. Huang, J. Lee, J. Vollbrecht, V. V. Brus, A. L. Dixon, D. X. Cao, Z. Zhu, Z. Du, H. Wang, K. Cho, G. C. Bazan and T. Q. Nguyen, Adv. Mater., 2020, 32, 1906027.

N. G. Chemmangattuvalappil, Curr. Opin. Chem. Eng., 2020, 27, 51-59.

A. I. Papadopoulos, G. Shavalieva, S. Papadokonstantakis, P. Seferlis, F. A. Perdomo, A. Galindo, G. Jackson and C. S. Adjiman, Comput. Chem. Eng., 2020, 135, 106769. T. Zhou, K. McBride, S. Linke, Z. Song and K. Sundmacher, Curr. Opin. Chem. Eng., 2020, 27, 35-44.

R. Xu, Y. H. Zhao, Q. Z. Han, P. G. Ning, H. Bin Cao and H. Wen, J. Clean. Prod., 2020, 277, 122334.

V. Gerbaud, The InBioSynSolv Project: Virtual laboratory for synthons and biosolvent design based on reverse molecular engineering, https://oatao.univtoulouse.fr/6246/.

Z. Li, L. Ying, P. Zhu, W. Zhong, N. Li, F. Liu, F. Huang and Y. Cao, Energy Environ. Sci., 2019, 12, 157-163.

J. Heintz, PhD thesis. Université de Toulouse, 2012.

Z. M. Manon Bergez-Lacoste, Sophie Thiebaud-Roux, Pascale De Caro, Jean-François Fabre, Vincent Gerbaud, Biofuels, Bioprod. Biorefining, 2012, 6, 246-256.

L. Moity, V. Molinier, A. Benazzouz, B. Joossen, V. Gerbaud and J. M. Aubry, Green Chem., 2016, 18, 3239-3249. M. T. Dos Santos, P. Morgavi and G. A. C. Le Roux, OCL, 2018, 25, D107.

C. C. Chueh, K. Yao, H. L. Yip, C. Y. Chang, Y. X. Xu, K. S. Chen, C. Z. Li, P. Liu, F. Huang, Y. Chen, W. C. Chen and A. K. Y. Jen, Energy Environ. Sci., 2013, 6, 3241-3248.

M. T. Dang, L. Hirsch and G. Wantz, Adv. Mater., 2011, 23, 3597-3602.

X. Ma, Q. An, O. A. Ibraikulov, P. Lévêque, T. Heiser, N. Leclerc, X. Zhang and F. Zhang, J. Mater. Chem. A, 2020, 8, 1265-1272.

O. A. Ibraikulov, C. Ngov, P. Chávez, I. Bulut, B. Heinrich, O. Boyron, K. L. Gerasimov, D. A. Ivanov, S. Swaraj, S. Méry, N. Leclerc, P. Lévêque and T. Heiser, J. Mater. Chem. A, 2018, 6, 12038-12045.

A. Wadsworth, Z. Hamid, M. Bidwell, R. S. Ashraf, J. I. Khan, D. H. Anjum, C. Cendra, J. Yan, E. Rezasoltani, A. A. Y. Guilbert, M. Azzouzi, N. Gasparini, J. H. Bannock, D. Baran, H. Wu, J. C. de Mello, C. J. Brabec, A. Salleo, J. Nelson, F. 
Laquai and I. McCulloch, Adv. Energy Mater., 2018, 8, 1801001.

K. N. Zhang, P. Q. Bi, Z. C. Wen, M. S. Niu, Z. H. Chen, T. Wang, L. Feng, J. L. Yang and X. T. Hao, Org. Electron., 2018, 62, 643-652.

S. Strohm, F. Machui, S. Langner, P. Kubis, N. Gasparini, M. Salvador, I. McCulloch, H. J. Egelhaaf and C. J. Brabec, Energy Environ. Sci., 2018, 11, 2225-2234. J. Heintz, J. P. Belaud, N. Pandya, M. Teles Dos Santos and V. Gerbaud, Comput. Chem. Eng., 2014, 71, 362-376. V. V. Luke E.K. Achenie, Rafiqul Gani, Computer Aided Molecular Design, Theory and Practice, Elsevierscience B.V. Amsterdam, 1st edn., 2002. B. E. Poling, J. M. Prausnitz and J. P. O'Connell, The properties of gases and liquids, McGraw-Hill Professional, the United States, 5, 2000. J. Marrero and R. Gani, Fluid Phase Equilib., 2001, 183-184 183-208. I. Rodriguez-Donis, S. Thiebaud-Roux, S. Lavoine and V. Gerbaud, Comptes Rendus Chim., 2018, 21, 606-621. Y. Zhang, G. Cai, Y. Li, Z. Zhang, T. Li, X. Zuo, X. Lu and Y. Lin, Adv. Mater., 2021, 2008134. D. Liu, Z. Wang, S. Zhang, Z. Zheng, B. Yang, W. Ma and J. Hou, RSC Adv., 2015, 5, 69567-69572. C. Sprau, F. Buss, M. Wagner, D. Landerer, M. Koppitz, A. Schulz, D. Bahro, W. Schabel, P. Scharfer and A. Colsmann, Energy Environ. Sci., 2015, 8, 2744-2752.

Z. Hamid, A. Wadsworth, E. Rezasoltani, S. Holliday, M. Azzouzi, M. Neophytou, A. A. Y. Guilbert, Y. Dong, M. S. Little, S. Mukherjee, A. A. Herzing, H. Bristow, R. J. Kline, D. M. DeLongchamp, A. A. Bakulin, J. R. Durrant, J. Nelson and I. McCulloch, Adv. Energy Mater., 2020, 10, 1903248. J. Munshi and G. Balasubramanian, Soft Mater., 2020, 18 163-176. H. Zhang, H. Yao, W. Zhao, L. Ye and J. Hou, Adv. Energy Mater., 2016, 6, 1502177. S. E. Shaheen, C. J. Brabec, N. S. Sariciftci, F. Padinger, T. Fromherz and J. C. Hummelen, Appl. Phys. Lett., 2001, 78, 841-843.

D. T. Duong, B. Walker, J. Lin, C. Kim, J. Love, B. Purushothaman, J. E. Anthony and T. Q. Nguyen, J. Polym. Sci. Part B Polym. Phys., 2012, 50, 1405-1413.

C. Liao, M. Zhang, X. Xu, F. Liu, Y. Li and Q. Peng, J. Mater. Chem. A, 2019, 7, 716-726.

L. Zhu, M. Zhang, G. Zhou, T. Hao, J. Xu, J. Wang, C. Qiu, N. Prine, J. Ali, W. Feng, X. Gu, Z. Ma, Z. Tang, H. Zhu, L. Ying, Y. Zhang and F. Liu, Adv. Energy Mater., 2020, 10, 1904234. C. M. Hansen, Hansen solubility parameters: a user's handbook, CRC Press, the United States, 2, 2007. S. Nilsson, A. Bernasik, A. Budkowski and E. Moons, Macromolecules, 2007, 40, 8291-8301.

E. Verploegen, C. E. Miller, K. Schmidt, Z. Bao and M. F. Toney, Chem. Mater., 2012, 24, 3923-3931.

S. Abbott, C. M. Hansen and H. Yamamoto, HSPiP 4th Edition version 4.1.07, Hansen Solubility Parameters in Practice Complete with eBook, Software and Data, CRC Press, Boca Raton FL, 4, 2013.
S. and S. E. Howell, Flammable and Combustible Liquid Hazard Classifications,

https://ehs.princeton.edu/laboratory-research/chemicalsafety/flammable-materials/flammable-and-combustibleliquid-hazard.

M. Karakawa, K. Suzuki, T. Kuwabara, T. Taima, K. Nagai, M. Nakano, T. Yamaguchi and K. Takahashi, Org. Electron., 2020, 76, 105448.

C. Shalu, M. Shukla, A. Tiwari, J. Agrawal, A. Bilgaiyan and V. Singh, Phys. E Low-Dimensional Syst. Nanostructures, 2020, 115, 113694.

P. S. James H. Clark, George A. Kraus, Andrzej Stankiewicz, Ed., Sustainable Solvents, 2017.

TCI AMERICA, https://www.chemblink.com/MSDS/MSDSFiles/766-972_TCl.pdf $\mathrm{CDH}$, https://www.cdhfinechemical.com/ ECHA, https://echa.europa.eu/ W. Zhao, L. Ye, S. Zhang, M. Sun and J. Hou, J. Mater. Chem. A, 2015, 3, 12723-12729.

I. C. Ghosekar and G. C. Patil, Semicond. Sci. Technol., 2021, 36, 045005.

U. Würfel, J. Herterich, M. List, J. Faisst, M. F. M. Bhuyian, H.-F. Schleiermacher, K. T. Knupfer and B. Zimmermann, Sol. RRL, 2021, 5, 2000802. 